\title{
Applying process-based models to the Borssele scenario
}

\author{
J.E. Brown ${ }^{1, *}$, N.A. Beresford ${ }^{2}$, A. Hosseini ${ }^{1}$ and C.L. Barnett ${ }^{2}$ \\ ${ }^{1}$ DSA - Norwegian Radiation and Nuclear Safety Authority, Østerås, Norway. \\ ${ }^{2}$ UKCEH - UK Centre for Ecology \& Hydrology, Lancaster, United Kingdom.
}

\begin{abstract}
The objective of this paper is to consider the implications of employing process-based models on predictions for radionuclide activity concentrations in grass and cow milk. The FDMT (Food Chain and Dose Module for Terrestrial Pathways as used in the JRODOS and ARGOS decision support systems) model has been transferred to a modelling platform enabling sub-models to be modified and replaced. Primarily, this has involved invoking process-based models for ${ }^{137} \mathrm{Cs}$ and ${ }^{90} \mathrm{Sr}$ that account for soil chemistry in simulating bioavailability and plant transfer. The implementation of such models can lead to quite dramatic differences in predicted activity concentrations of radionuclides in grass and milk compared to a default FDMT set-up for time periods later than a few weeks post deposition. Considering transfer within a spatial context, by combining information from the outputs of process-based models with illustrative soil maps, leads to the observation that the most elevated ${ }^{137} \mathrm{Cs}$ and ${ }^{90} \mathrm{Sr}$ concentrations in grass and milk might not necessarily occur in areas where deposition is highest. Not accounting for soil type when modelling food chain transfer might lead to the sub-optimal allocation of resources or misidentification of the most vulnerable areas in the long-term after an accidental release.
\end{abstract}

Keywords: food chain / transfer $/{ }^{137} \mathrm{Cs} /{ }^{90} \mathrm{Sr} /$ countermeasures

\section{Introduction}

The scenario involving an accidental release of radioactivity from the Borssele 1 reactor is described in De Vries et al. (2019). The datasets on deposition from these simulations constitute the starting point for the agricultural food chain modelling described in this article.

The FDMT (Food Chain and Dose Module for Terrestrial Pathways) is a model developed to simulate transfer of radionuclides along the human food chain and to calculate activity concentrations in both human food products and animal feedstuffs. It is the food chain transfer module used in the European JRODOS and ARGOS decision support systems (see Brown et al., 2018). FDMT is largely based upon the earlier dynamic model ECOSYS-87 (Müller and Pröhl, 1993), which was originally implemented within Microsoft EXCEL $^{\mathrm{TM}}$. Much of the developmental work including the numerical specification of many of the parameters used in ECOSYS-87 (and therefore FDMT) was completed in the 1980 s and hence many of the later, large number of radioecology studies, prompted by the 1986 Chernobyl accident, were not considered. This latter shortcoming has been addressed, to a degree, within the CONFIDENCE project

\footnotetext{
*Corresponding author: justin.brown@dsa.no
}

(Brown et al., 2018) and elsewhere (Staudt, 2016; Thørring et al., 2016).

As described in Brown et al. (2018), there are numerous limitations associated with the FDMT model as incorporated within the decision support systems. Amongst these, are a lack of flexibility with regards to modifying model components and the assessor being restricted to only run simulations deterministically. Overcoming these restrictions has provided the rationale for extracting the model and implementing it within a probabilistic-enabled modelling platform called ECOLEGO which is a platform for creating dynamic models and performing deterministic or probabilistic simulations (Avila et al., 2005; http://ecolego.facilia.se/ecolego/show/ HomePage). In so doing, more simulation options were introduced further enabling an exploration of the factors that introduce variability within model predictions, e.g. regionspecific parameters such as growing seasons and dietary habits (Brown et al., 2018).

The objectives of the study described here were to implement process-based models for the soil to plant transfer of ${ }^{137} \mathrm{Cs}$ and ${ }^{90} \mathrm{Sr}$ (Almahayni et al., 2019) to explore what difference the application of such models makes for predictions of radionuclide activity concentrations in grass and cow milk, compared to the standard default models used in FDMT (see Howard et al., 2002). Furthermore, the objective was to link this food chain modelling work to earlier release 
scenarios and advection-dispersion modelling developed for CONFIDENCE (De Vries et al., 2019) so that implications for replacing FDMT default models with the process-based models could be considered in a spatial context. The final objective was to explore the efficacy of countermeasures, specifically fertiliser application.

\section{Methodology}

Transferring FDMT to the ECOLEGO platform provided us with flexibility to modify and develop the existing models by either including new processes or adding sub-models. For the present work, the default soil model of FDMT has been replaced by the "Absalom" soil-to-plant transfer model, which predicts ${ }^{137} \mathrm{Cs}$ in soil solution and grass with time. The mathematical specification of Absalom et al. (2001) model as presented in Appendix 1 of Tarsitano et al. (2011) is the version that has been implemented within the ECOLEGO platform (after fixing some errors in Tarsitano et al. (2011) in consultation with the originating authors). Inputs for the "Absalom" model are soil gravimetric clay content $(\mathrm{g} / \mathrm{g})$, gravimetric organic content $(\mathrm{g} / \mathrm{g})$, $\mathrm{pH}$ and exchangeable potassium $\left(\mathrm{cmolc} / \mathrm{kg}\right.$ ). For ${ }^{90} \mathrm{Sr}$, the underlying FDMT soil and soil to plant model has been retained but the soil to plant transfer factor (TF) characterising the transfer of radiostrontium from soil to grass has been replaced by soilspecific values derived from a simple model, based on dry matter (DM) Ca concentrations in crops and soil as described elsewhere (Almahayni et al., 2019). This model is a simplification in the sense that, although it provides soil specific TFs, it otherwise utilises generic FDMT parameters for soil processes (e.g. migration/leaching out of the rooting zone, fixation and desorption) that in reality will have some dependency on soil type.

A further modification has been made to allow exchangeable potassium concentrations to be input as time-dependent variables to meet a requirement for the influence of $\mathrm{K}$-fertiliser applications to be considered. In practice, this was achieved by replacing a single deterministic value for exchangeable potassium concentrations by a "look-up table", within the ECOLEGO modelling environment, expressed as changing $[\mathrm{K}]$ levels with time, the profile for which can be repeated annually.

\subsection{Borssele 1 scenario}

As inputs to the models a deposition of $1 \mathrm{kBq} \mathrm{m}^{-2}$ for both ${ }^{137} \mathrm{Cs}$ and ${ }^{90} \mathrm{Sr}$ were used. The deposition was assumed to occur purely by wet deposition, i.e. the integrated air concentration (and therefore dry deposition level) was set to zero. The amount of rainfall was set to $3 \mathrm{~mm}$ and the deposition date was specified as the 2nd July.

With the exception of changes to the soil and soil to plant sub-models as described above, all FDMT parameters, such as those related to leaf area index (or yield) at a given date, the transfer of $\mathrm{Cs}$ and $\mathrm{Sr}$ from the cow diet to milk, and animal feeding regimes were assigned default values. Although this may introduce some errors in the output, for example small differences in the timing between the Netherlands (Calder Stewart, 2018) and Southern Germany (upon which the default FDMT parameters are based) with regards to when cattle are released onto pasture and brought back into shelter, these are not considered to be substantial. Model simulations were run for 10000 days (approximately 27 years) following the deposition event. Endpoints selected for model runs were ${ }^{90} \mathrm{Sr}$ and ${ }^{137} \mathrm{Cs}$ activity concentration in grass and milk.

Deposition magnitudes had been calculated via the application of an atmospheric advection-dispersion model, as used in the JRODOS system, to a source term defined for the Borssele nuclear power plant (NPP) in the Netherlands De Vries et al. (2019). The spatial deposition pattern was provided as a 2-dimension grid with each grid cell having a specified ${ }^{137} \mathrm{Cs}$ and ${ }^{90} \mathrm{Sr}$ deposition level for subsequent processing. Further details are provided in De Vries et al. (2019). For the purposes of this demonstration, we extracted the deposition data approximating to the area of the Walcheren-ZuidBeveland-Noord-Beveland Peninsula (on which the Borssele NPP is located) (Fig. 1). For clarity in Figure 1, and all subsequent maps, we only present those cells for which there was predicted deposition of radionuclides.

The transfer of ${ }^{137} \mathrm{Cs}$ and ${ }^{90} \mathrm{Sr}$ from soil to grass (i.e. "rootuptake"), when using the alternative models described above, is dictated by soil type. The first step in the analysis of data was to provide a soil map defining the intersection of the deposition plume from the Borssele 1 scenario with the soils over which the deposition was predicted to occur. For demonstration purposes, here we have defined a soil map for the area based upon five diverse, though not extreme, soils for which we had all the required parameters (see Almahayni et al., 2019) (Tab. 1; Fig. 2). We have to stress that this does not represent the actual distribution of soils in the assessment area (it is purely for demonstration purposes). That said the soils are likely to be broadly representative of those found in the Netherlands (van den Berg et al., 2017).

For the purposes of converting radionuclide deposition values $\left(\mathrm{Bq} \mathrm{m}^{-2}\right)$ to radionuclide activity concentrations, a soil bulk density was required; this was not available for the five soils therefore values likely to be appropriate for each of the soil types were used.

The "Absalom" and Sr-TF in FDMT models were run for each specific soil type and these outputs (for a unit deposition) were mapped onto the corresponding soil according to the spatial distributions specified in the gridded map (Fig. 2 above). The intersection with the radionuclide deposition grid cells could be specified and the outputs from the "Absalom" and Sr-TF in FDMT models could thus be scaled appropriately to the corresponding deposition magnitude for each cell.

\subsection{Fertiliser application scenarios}

A K-fertiliser application rate as a countermeasure strategy of $100 \mathrm{~kg} \mathrm{ha}^{-1}$ has been used based upon (Beresford et al., 2005). Two modelling scenarios have been selected:

- apply $100 \mathrm{~kg}$ of $\mathrm{K}$ per ha in October every year;

- apply $100 \mathrm{~kg}$ of $\mathrm{K}$ per ha at start of April every year, starting in the year of deposition.

The October date was selected as this approximates to the likely normal fertilisation time; best practice advice for grazed pastures being that $\mathrm{K}$ fertilisation is conducted at this time of year, if possible, to avoid potential problems with animal mineral balances (Wall and Plunkett, 2016). The April date was selected as this corresponds to around about the time when 
Table 1. Characteristics and estimated $\mathrm{Sr}(\mathrm{DM}) \mathrm{TF}$ values for the study soils.

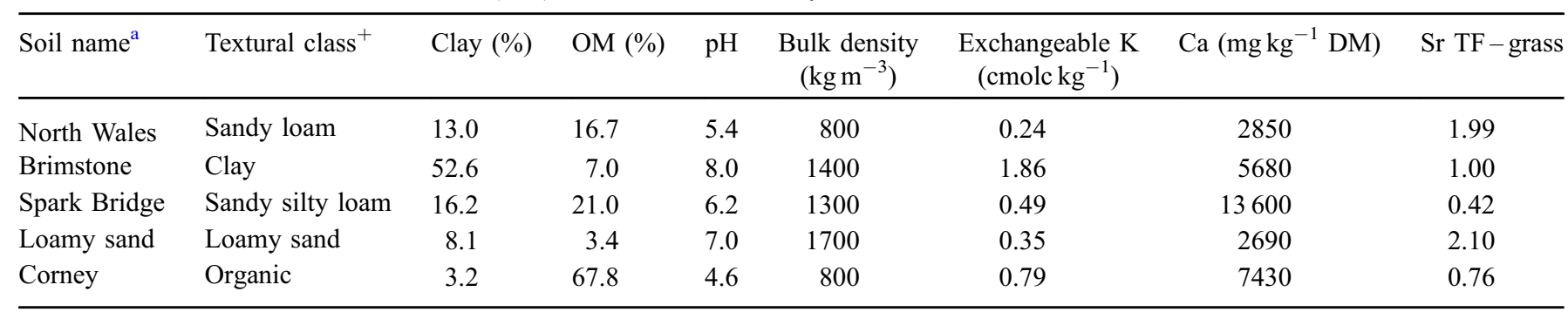

animals may start to graze pastures after winter housing and from a radioecological perspective may be expected to have a greater effect on ${ }^{137} \mathrm{Cs}$ levels in vegetation.

Concentrations of (fertiliser-sourced) exchangeable $\mathrm{K}$ were derived by dividing the amount of added $\mathrm{K}(100 \mathrm{~kg}$ converted to its equivalent in units of cmolc) by the area $\left(10000 \mathrm{~m}^{2}\right.$, or $\left.1 \mathrm{ha}\right)$, the depth over which Cs is assumed to be initially distributed in the "Absalom" model $(0.025 \mathrm{~m})$ and the assumed soil-specific bulk density (Tab. 1). This initial "spike" in exchangeable $\mathrm{K}$ concentrations above the background levels (Tab. 1) were then assumed to decrease linearly over the following year returning to background levels within this period.

\section{Results}

\subsection{Radionuclide levels in grass}

Activity concentrations of radionuclides in grass over time are presented in Figure 3.

Cs-137 activity concentrations in grass (Fig. 3a) are more or less identical for all soil types with the exception of organic soils for the initial period up to several weeks demonstrating the overriding importance of processes related to the interception by, and weathering from, vegetation (i.e. foliar uptake processes as referred to by FDMT) at this stage. Organic soils exhibit some influence of root uptake even within the first weeks of simulation. The FDMT default provides similar output to both the sandy silty loam and loamy sand soil simulations at almost all time points. The largest difference (between these similar model results) is observed at: (i) around 2500 days when FDMT provides an output approximately two times the loamy sand value; and (ii) at the end of the simulation where the sandy silty loam output is approximately 1.7 times the FDMT value. The outputs of ${ }^{137} \mathrm{Cs}$ in grass for the other three soil types are more divergent from the corresponding FDMT values, especially for the organic soil. Whereas at the end of the simulation, the ${ }^{137} \mathrm{Cs}$ activity concentration in grass for the organic soil is approximately 130 times the FDMT value, that for the clay soil is approximately 0.2 times the FDMT value. The clay soil, which had the highest exchangeable $[\mathrm{K}]$ and highest gravimetric clay content, exhibits the lowest ${ }^{137} \mathrm{Cs}$ transfer to grass. The difference in predictions across all soil types is substantial, with the organic soil exhibiting a predicted ${ }^{137} \mathrm{Cs}$ activity concentration in grass near to 670 times the levels observed for the clay soil at the end of the simulation.

Sr-90 activity concentrations in grass (Fig. 3b) show a similar temporal pattern to that observed for ${ }^{137} \mathrm{Cs}$ although the absolute
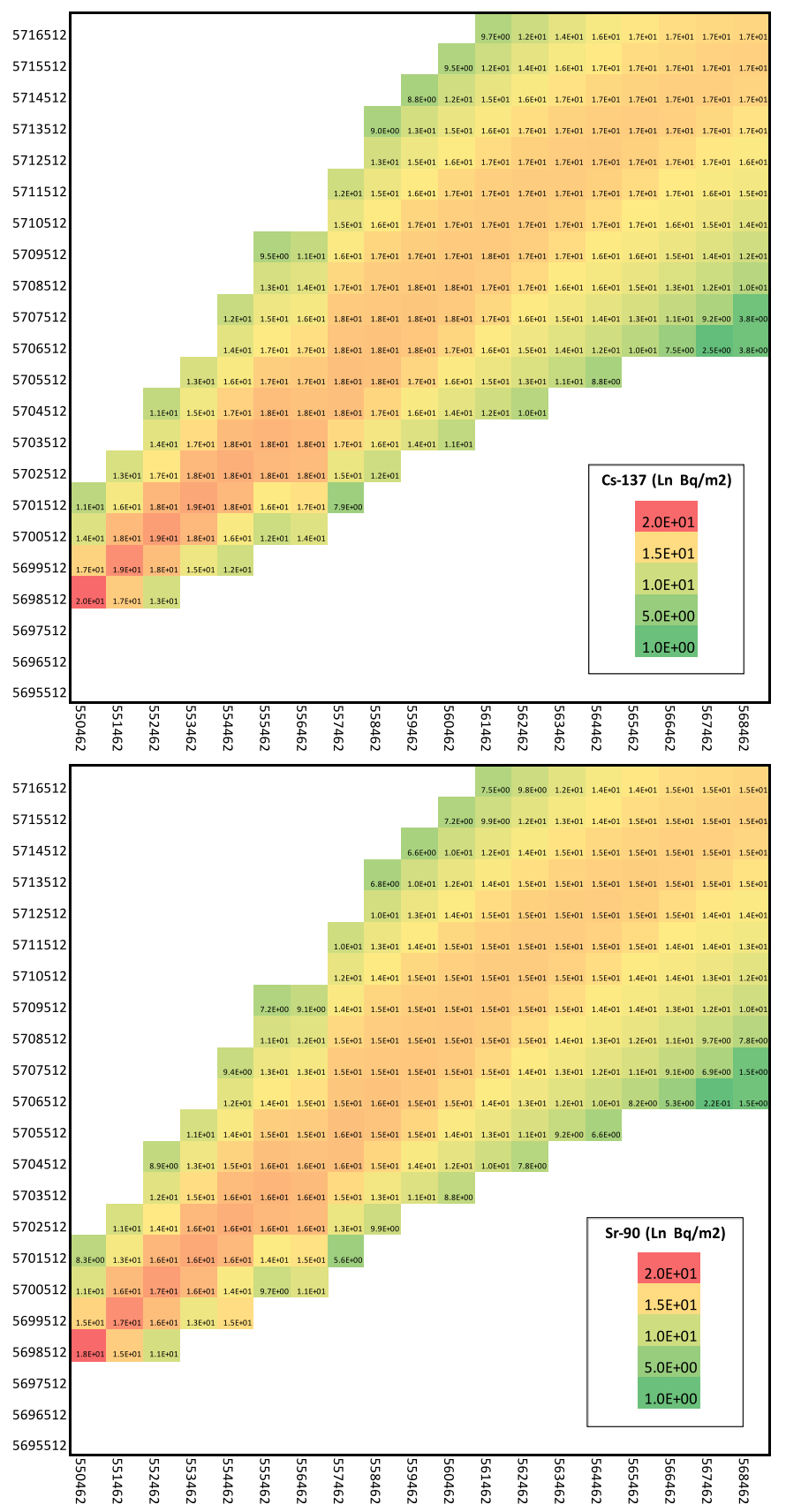

Fig. 1. Deposition maps for ${ }^{137} \mathrm{Cs}$ and ${ }^{90} \mathrm{Sr}\left(\mathrm{Bqm}^{-2}\right)$ used in the assessment. Note the values are reported as natural logarithm, In (deposition). Each cell covers an area of $1 \mathrm{~km}^{2}$. Values in the legend key represent maxima for each colour band. 


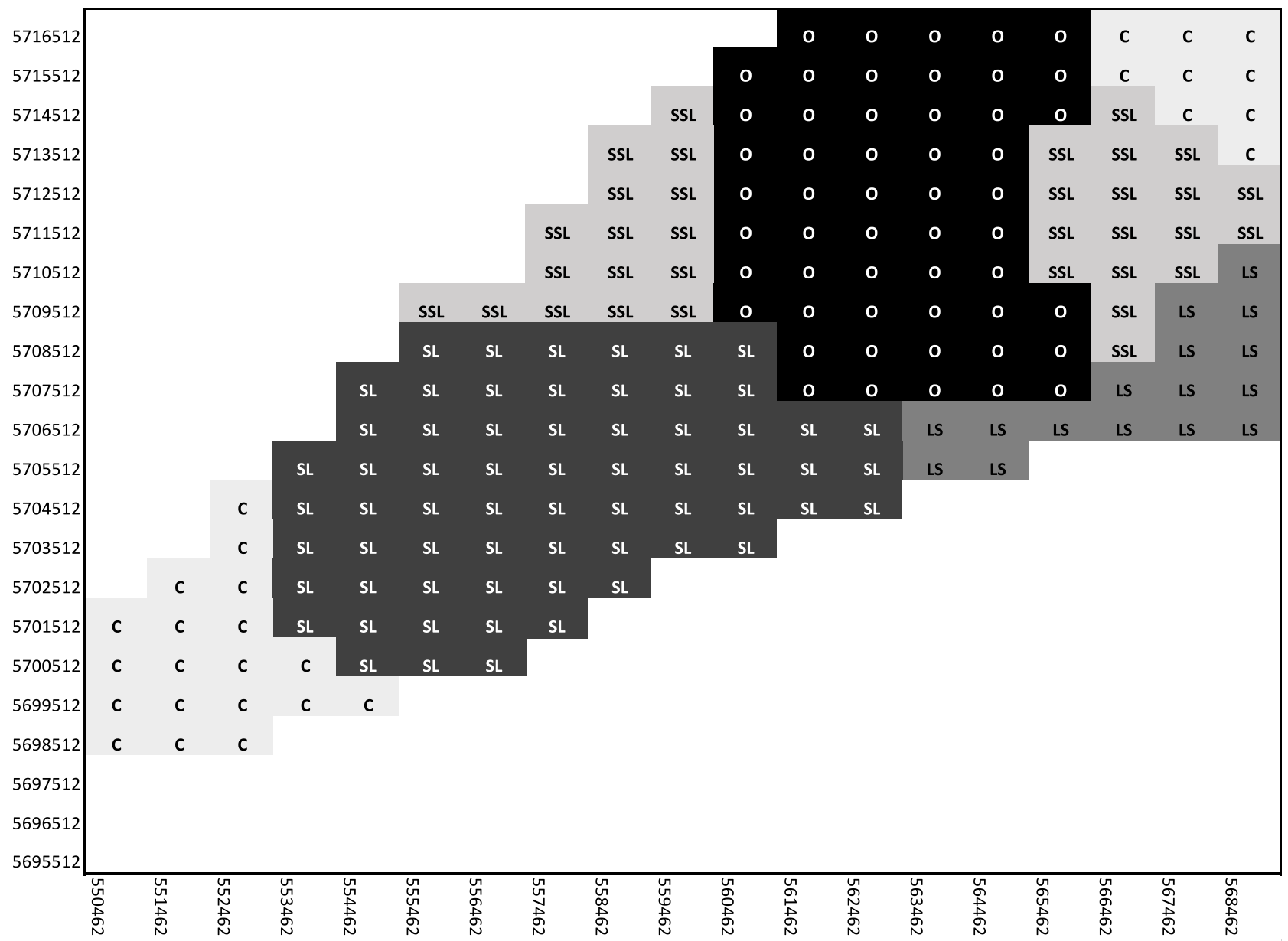

Fig. 2. Soil map showing the grid of spatial soil categorisations $(\mathrm{C}=$ clay; $\mathrm{SL}=$ sandy loam; $\mathrm{SSL}=$ sandy silty loam; $\mathrm{LS}=\mathrm{loamy}$ sand; $\mathrm{O}=$ organic) as used in the assessment. Cell size equates to $1 \mathrm{~km}^{2}$.
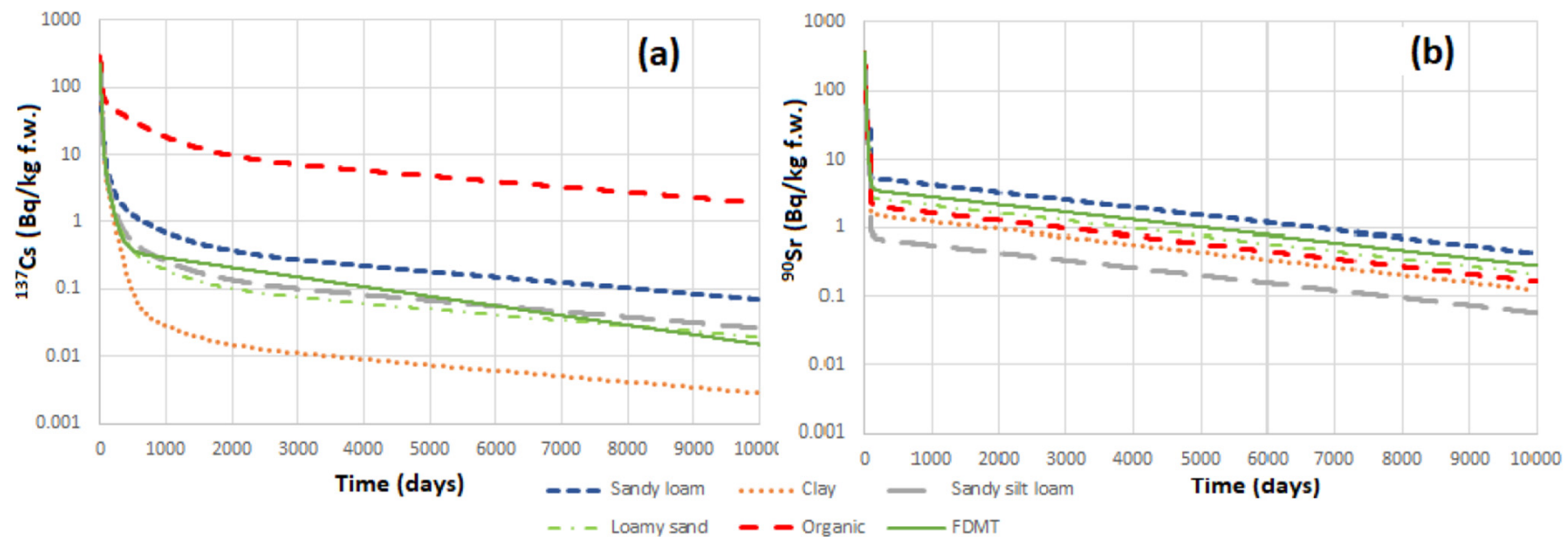

Fig. 3. Activity concentrations (fresh weight, f.w.) of (a) Cs-137 and (b) Sr-90 in grass versus time for a $1 \mathrm{kBq} \mathrm{m}^{-2}$ wet deposition occurring on July 2nd. Results are shown for five defined soil types (simulations from the "Absalom" model for Cs and simple soil-specific model for Sr) and for a generic soil using the FDMT "default".

levels, following the initial rapid decline, are higher than those predicted for radiocaesium for all soil types apart from the organic category. For the organic soil, transfers of ${ }^{137} \mathrm{Cs}$ to grass are higher than those for ${ }^{90} \mathrm{Sr}$. Whereas, the most elevated transfer of ${ }^{90} \mathrm{Sr}$ to grass is predicted to occur for the sandy loam, the lowest ${ }^{90} \mathrm{Sr}$ predictions occur for sandy silty loam. Organic soils do not exhibit particularly elevated transfer of ${ }^{90} \mathrm{Sr}$ to grass, falling roughly in the middle of the range expressed for ${ }^{90} \mathrm{Sr}$ over 


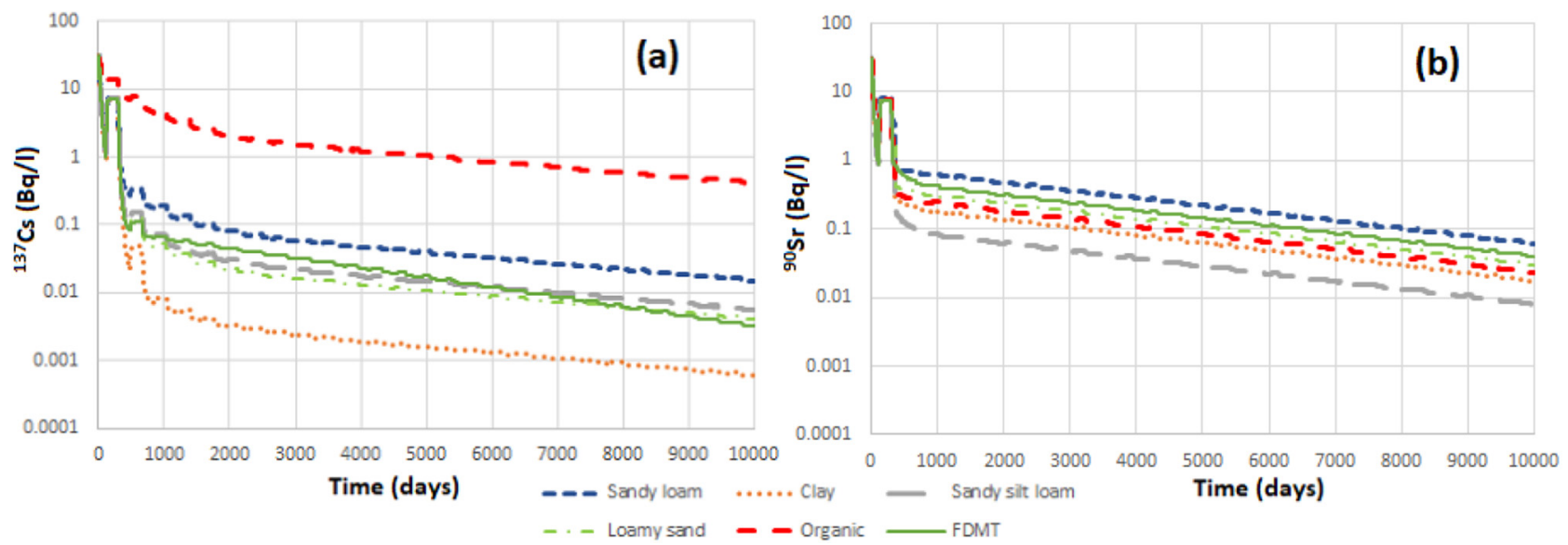

Fig. 4. Activity concentrations of (a) Cs-137 and (b) Sr-90 in milk versus time for a $1 \mathrm{kBq} \mathrm{m}^{-2}$ wet deposition occurring on July $2 \mathrm{nd}$. Results are shown for five defined soil types (simulations from the "Absalom" model and simple soil-specific model for Sr) and for a generic soil using the FDMT "default".

all soil types, in stark contrast to the exceptionally high transfer of ${ }^{137} \mathrm{Cs}$ to grass for organic soil compared to other soil types. Differences in the ${ }^{90} \mathrm{Sr}$ transfer to grass on the different soils largely reflect the differences in Ca status although bulk density also contributes up to two-times to differences in grass concentrations (Tab. 1). It is notable that the predictions made for ${ }^{90} \mathrm{Sr}$ transfer to grass using default FDMT TFs fall towards the top of the range expressed by the five soil types considered in this simulation (only sandy loam is higher). The difference in ${ }^{90} \mathrm{Sr}$ levels in grass over all soil types is far less pronounced than that observed for ${ }^{137} \mathrm{Cs}$ but is still substantial. At the end of the simulation period, the sandy loam has a predicted ${ }^{90} \mathrm{Sr}$ activity concentration in grass that is approaching an order of magnitude higher than that predicted for the sandy silty loam soil.

\subsection{Radionuclide levels in milk}

Activity concentrations of radionuclides in milk over time are presented in Figure 4.

The differences in the temporal profiles for activity concentrations of ${ }^{137} \mathrm{Cs}$ and ${ }^{90} \mathrm{Sr}$ in milk of cows pasturing on the different soil types tend to follow those simulated for grass. However, in contrast to the model results for grass, a subtle seasonal pattern in radionuclide activity concentrations simulated for milk is introduced reflecting the change from a grass diet in summer to hay in winter. The radionuclide activity concentrations in hay correspond to those in grass for specified harvesting periods (accounting for decay). This is a divergence from the original FDMT, where for practical reasons, after the third calendar year, no seasonal variations are considered: only an average annual contamination is calculated.

\subsection{Implications for spatial distributions of predicted radionuclide concentrations in milk}

Results from combining the deposition data with the results from the FDMT and process-based models, with the latter accounting for the mapped soil type, are presented in Figure 5.

The spatial patterns in contamination illustrate that the most elevated ${ }^{137} \mathrm{Cs}$ activity concentrations in milk might not necessarily be associated with areas of maximum deposition. Whereas, the FDMT model permits no distinction to be made between different soil types and therefore provides predictions where ${ }^{137} \mathrm{Cs}$ activity concentrations in milk correlate with deposition levels, the "Absalom" set up predicts the most elevated ${ }^{137} \mathrm{Cs}$ activity concentrations in milk to occur at some distance from areas of maximum deposition over areas characterised by organic soil with ${ }^{137} \mathrm{Cs}$ deposition levels about one order of magnitude lower than those closer to the Borssele NPP on clay soil types. Elevated milk activity concentrations are also observed over sandy loam soil with levels higher than those predicted for the more contaminated clay soil closer to the NPP. Our predicted results demonstrate that not accounting for soil type when modelling food chain transfer might lead to the misallocation of resources or misidentification of the most vulnerable areas. A similar relative spatial pattern, when comparing FDMT and the soilspecific simple Sr model, can be observed in predictions of ${ }^{90} \mathrm{Sr}$ activity concentrations in milk $\left(\mathrm{Bq} \mathrm{l}^{-1}\right)$ at 5 years. Although, in this case, both models predict the most elevated ${ }^{90} \mathrm{Sr}$ milk concentrations to occur closest to the source along the plume axis (i.e. grid point of maximum deposition), a similar spatial shift (to ${ }^{137} \mathrm{Cs}$ ) is observed with relatively elevated ${ }^{90} \mathrm{Sr}$ levels at considerable distances away from the release point (coinciding with sandy loam soils for which $\mathrm{Sr}$ transfer is relatively high).

\subsection{Countermeasures-application of $K$ fertiliser and transfer of ${ }^{137} \mathrm{Cs}$ to grass}

Results from the simulations following the wet deposition scenario occurring in early July and application of $\mathrm{K}$ fertiliser in April (and each following April thereafter) are presented in Figure 6. A similar temporal profile is observed for the application of fertiliser in October.

The application of $\mathrm{K}$ fertiliser is predicted to make a substantial difference to ${ }^{137} \mathrm{Cs}$ activity concentrations in grass for soils with relatively low exchangeable $\mathrm{K}$ concentrations (e.g. the sandy loam soil). In contrast, the application of fertiliser appears to make little difference to soil-grass ${ }^{137} \mathrm{Cs}$ 

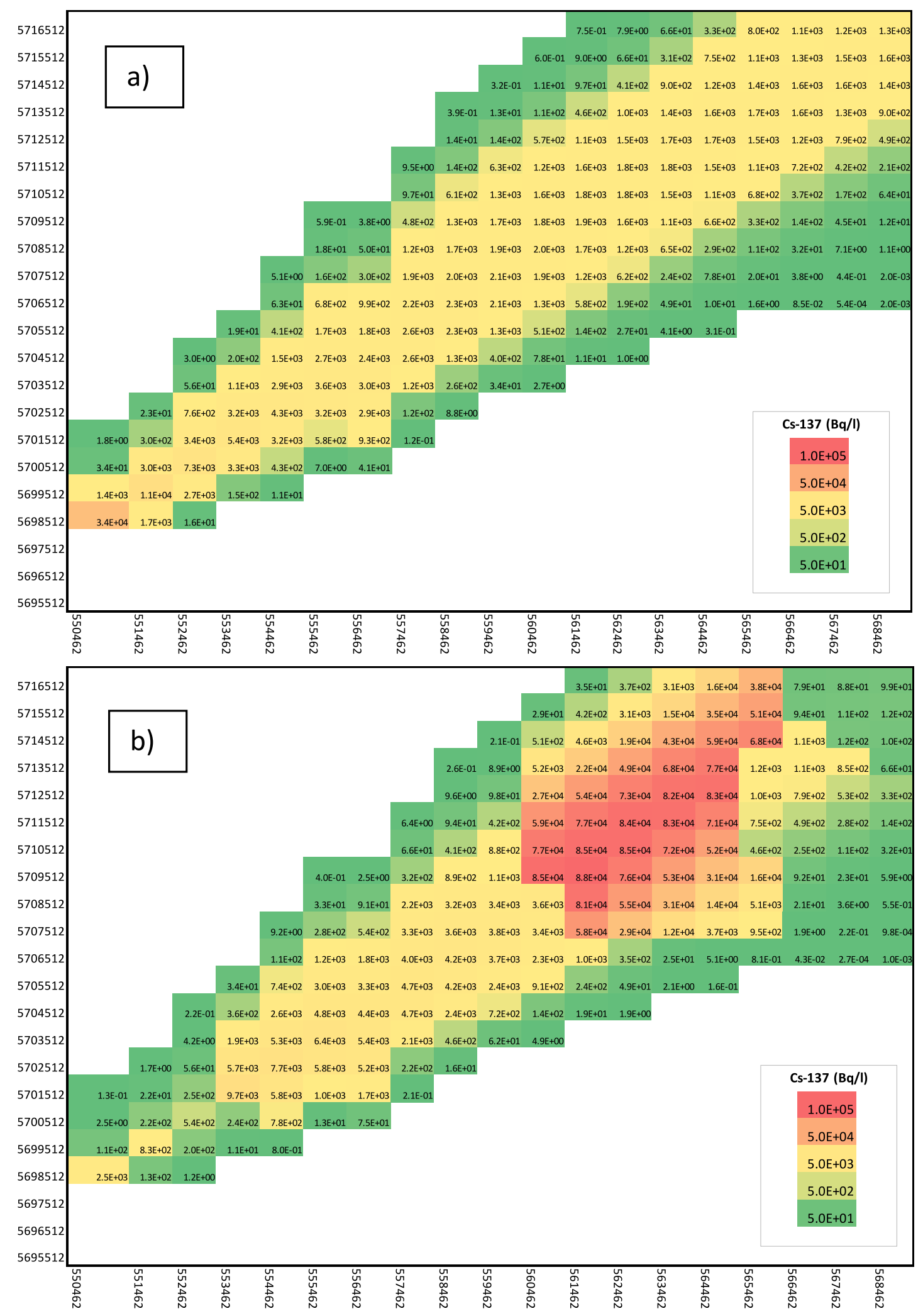

Fig. 5. Predictions of ${ }^{137} \mathrm{Cs}$ activity concentrations in milk $\left(\mathrm{Bq}^{-1}\right)$ at 5 years for (a) FDMT and (b) process based ("Absalom") using the soil categorisations as described earlier (Fig. 2). Each cell covers an area of $1 \mathrm{~km}^{2}$. Values in the legend key represent maxima for each colour band. 


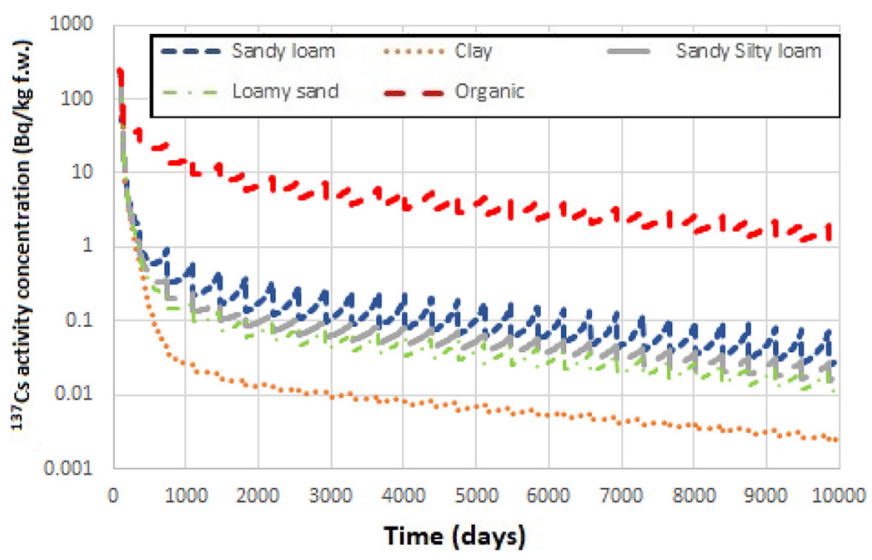

Fig. 6. Activity concentration of ${ }^{137} \mathrm{Cs}$ in grass $\left(\mathrm{Bq} \mathrm{kg}^{-1}\right.$ f.w.) with time after deposition following application of fertiliser in April of the year of deposition (and each following April thereafter).

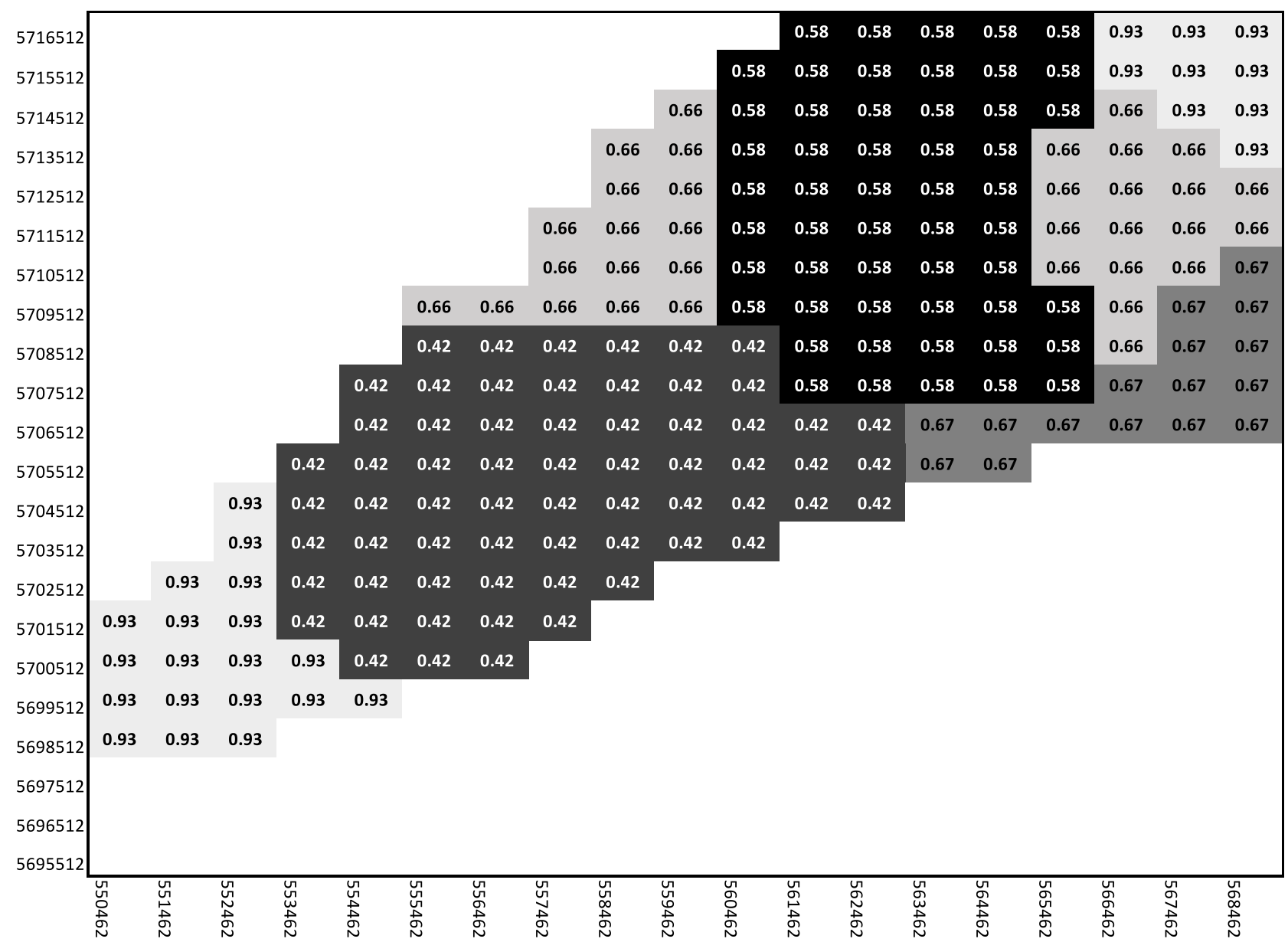

Fig. 7. Ratio of ${ }^{137} \mathrm{Cs}$ activity concentrations (April fertilisation:no fertilisation) in grass 13 months after deposition. Each cell covers an area of $1 \mathrm{~km}^{2}$.

transfer to clay soil where existing levels of exchangeable $\mathrm{K}$ are already relatively high. The form of the ${ }^{137} \mathrm{Cs}$ time profiles are "serrated", exhibiting decreases in ${ }^{137}$ Cs levels at time points corresponding to annual applications of fertiliser (Fig. 6).
Using the scenario as described above, it is possible to explore the efficacy of applying fertiliser from a spatial perspective (Fig. 7). Although these data are not based on the actual situation in the environs of Borssele 1 NPP, the information provided can be used to illustrate a point. For the 
given example, a circa two-fold reduction can be seen for some areas, whereas at other locations the reduction in ${ }^{137} \mathrm{Cs}$ activity concentrations are negligible. The spatial pattern corresponds to the differences predicted for different soils types (largely driven by exchangeable [K] status) as discussed above. Under the simple scenario considered here the reduction in ${ }^{137} \mathrm{Cs}$ activity concentrations in milk would be similar to those in grass whilst animals were grazing pastures. Although, as we note above, the temporal pattern showing changes in ${ }^{137} \mathrm{Cs}$ activity concentrations in grass is similar for both April and October fertilisation, the reduction in milk ${ }^{137} \mathrm{Cs}$ activity concentrations is a little less for October compared to April fertilisation in the subsequent grazing season. For instance, if we model K-fertilisation in the October of the year of deposition the maximum reduction in milk ${ }^{137} \mathrm{Cs}$ concentrations 13 months after deposition (i.e. comparable to Fig. 7) is by less than $50 \%$. This is because exchangeable $[\mathrm{K}]$ concentrations are modelled as decreasing with time after fertilisation. Whereas the main impact of the April application of fertiliser is seen as a reduction in levels during the grass growing and hay harvesting period, this being reflected in lower milk levels; the main predicted impact on ${ }^{137} \mathrm{Cs}$ activity concentrations in grass for the October application of fertiliser occurs in the winter months when cattle are assumed to be housed and being fed conserved forage.

\section{Conclusions}

In the short-term (up to a few months following a release of radioactivity), process-based soil-plant models (for $\mathrm{Cs}$ and $\mathrm{Sr}$ ) appear generally to give no added benefit, i.e. models such as FDMT are sufficient for predictions during this phase because soil-plant transfer contributes little to radionuclide activity concentrations of grass in the short-term. An exception may exist for the transfer of ${ }^{137} \mathrm{Cs}$ to grass growing over organic soils where the influence of highly enhanced root uptake is apparent even at early stages in the simulations (i.e. within the first month). In contrast, should predictions of food chain transfer be required at later stages, i.e. months and years following a deposition event, the application of process-based soil to plant transfer models in some cases provide considerably different results to those generated using a default FDMT set up. The advantage of using process-based soil-plant models is that they account for soil chemistry which influences transfer to the food chain. For the example given here, using the FDMT default as opposed to a model accounting for soil type, might have led to a substantial underprediction of ${ }^{137} \mathrm{Cs}$ in grass (by a factor of more than 100) for periods several years following a deposition event. Combining soil type maps with bespoke process-based soilplant models has obvious utility in terms of identifying where food products are likely to remain contaminated in the longerterm. Furthermore, this facilitates the task of establishing where countermeasures, such as fertiliser application, may be best employed.

Acknowledgement. The work described in this paper was conducted within the CONFIDENCE project which was part of the CONCERT project. This CONCERT project received funding from the Euratom Research and Training programme (2014-2018) under grant agreement No. 662287. The inputs of
J.E. Brown and A. Hosseini were partly supported by the Research Council of Norway through its Centres of Excellence funding scheme (project number 223268/F50). The authors would like to thank all participants of CONFIDENCE WP3 and also Prof. Neil Crout (University of Nottingham) for discussions on the "Absalom" model.

Disclaimer (Art. 29.5 GA). This publication reflects only the author's view. Responsibility for the information and views expressed therein lies entirely with the authors. The European Commission is not responsible for any use that may be made of the information it contains.

\section{References}

Absalom JP, Young SD, Crout NMJ, Sanchez A, Wright SM, Smolders E, Nisbet AF, Gillett AG. 2001. Predicting the transfer of radiocaesium from organic soils to plants using soil characteristics. J. Environ. Radioact. 52: 31-43. https://doi.org/10.1016/ S0265-931X(00)00098-9.

Almahayni T, Sweeck L, Beresford NA, Barnett CL, Lofts S, Hosseini A, Brown J, Thørring H, Guillén J. 2019. An evaluation of processbased models and their application in food chain assessments. CONCERT Deliverable D9.15. Available from https://concerth2020.eu/en/Publications.

Avila R, Broed R, Pereira A. 2005. ECOLEGO-A toolbox for radioecological risk assessment. In: Proceedings of the International Conference on the Protection from the Effects of Ionizing Radiation. IAEA-CN-109/80. pp. 229-232. Stockholm: International Atomic Energy Agency.

Beresford NA, Howard BJ, Barnett CL, Rantavaara A, Rissanen K, Reales N, Gallay F, Papachristodoulou C, Ioannides K, Nisbet AF, Hesketh N, Oughton D, Bay I. 2005. Compendium of countermeasures for the management of food production systems. EURANOS Deliverable TN(05)-01 (including CD). Brussels: EC.

Brown JE, Avila R, Barnett CL, Beresford NA, Hosseini A, Lind O-C, Oughton DH, Perez D, Salbu B, Teien HC, Thørring H. 2018. Improving models and learning from post-Fukushima studies. CONCERT Deliverable D9.13. Available from https://concerth2020.eu/en/Publications.

Calder Stewart. 2018. Dairy farming in the Netherlands Part 2. Available from https:/www.dairybarnsystems.co.nz/knowledgecentre/deventer-dairy-farms/.

De Vries H, Geertsema G, Korsakissok I, Périllat R, Scheele R, Tomas J, Andronopoulos S, Astrup P, Bedwell P, Charnock T, Hamburger T, Ievdin I, Leadbetter S, Pázmándi T, Rudas C, Sogachev A, Szántó P, Wellings J. 2019. Published sets of probability maps of threshold exceedance for scenarios provided to WP4, WP5 \& $W P 6 \rightarrow 2$. CONCERT Deliverable D9.4. Available from https:// concert-h2020.eu/en/Publications.

Howard BJ, Strand P, Assimakopoulos P, Bréchignac F, Gascó C, Métivier H, Moberg L, Smith JT, Tamponnet C, Trueba C, Voigt G, Wright S. 2002. Estimation of radioecological sensitivity. Radioprotection 37: 1167-1173. https://doi.org/10.1051/radiopro/ 2002142.

Müller H, Pröhl G. 1993. ECOSYS-87: A dynamic model for assessing radiological consequences of nuclear accidents. Health Phys. 64: 232-252. https://doi.org/10.1097/00004032-199303000-00002.

Staudt C. 2016. HARMONE Database with values for geographically dependent parameters. OPERRA Deliverable D5.36. Brussels: EC.

Tarsitano D, Young SD, Crout NMJ. 2011. Evaluating and reducing a model of radiocaesium soil-plant uptake. J. Environ. Radioact. 102: 262-269. https://doi.org/10.1016/j.jenvrad.2010.11.017. 
Thørring H, Dyve J, Hevrøy T, Lahtinen J, Liland A, Montero M, Real A, Simon-Cornu M, Trueba C. 2016. Sets of improved parameter values for Nordic and Mediterranean ecosystems for Cs-134/137, Sr-90, I-131 with justification text. COMET Deliverable IRAHuman-D3. Brussels: EC.

van den Berg F, Tiktak A, Hoogland T, Poot A, Boeston JJTI, van der Linden AMA, Pol JW. 2017. An improved soil organic matter map for GeoPEARL_NL; model description of version 4.4 .4 and consequences for the Dutch decision tree on leaching to groundwater. Report 2816, p. 56. Wageningen: Wageningen Environmental Research.

Wall DP, Plunkett M. (Eds.). 2016. Major and micro nutrient advice for productive agricultural crops. 4th Edn. Wexford: Teagasc, Johnstown Castle, Co. Available from https://www. teagasc.ie/media/website/publications/2016/soil-fertilitygreen.pdf.

Cite this article as: Brown JE, Beresford NA, Hosseini A, Barnett CL. 2020. Applying process-based models to the Borssele scenario. Radioprotection 55(HS1): S109-S117 